\title{
Impact of a Dutch urban regeneration programme on mental health trends: a quasi-experimental study
}

\author{
Birthe Jongeneel-Grimen, ${ }^{1}$ Mariël Droomers, ${ }^{1}$ Daniëlle Kramer, ${ }^{1}$ Jan-Willem Bruggink, ${ }^{2}$ \\ Hans van Oers, ${ }^{3,4}$ Anton E Kunst, ${ }^{1}$ Karien Stronks ${ }^{1}$
}

- Additional material is published online only. To view please visit the journal online (http://dx.doi.org/10.1136/jech2015-207016).

${ }^{1}$ Department of Public Health, Academic Medical Center, University of Amsterdam, Amsterdam, The Netherlands ${ }^{2}$ Statistics Netherlands, Heerlen, The Netherlands ${ }^{3}$ Centre for Public Health Status and Forecasting, National Institute for Public Health and the Environment, Bilthoven, The Netherlands ${ }^{4}$ Faculty of Social Sciences, Academic Collaborative Centre for Public Health Brabant, Tranzo, Tilburg University, Tilburg, The Netherlands

\section{Correspondence to} Professor Karien Stronks, Department of Public Health, Academic Medical Center, Meibergdreef 15, Amsterdam 1105 AZ, The Netherlands; k.stronks@amc.uva.nl

Received 27 November 2015 Revised 12 March 2016 Accepted 15 March 2016 Published Online First 6 April 2016

\section{ABSTRACT \\ Background This paper aims to assess the mental health impact of an urban regeneration programme implemented from 2008 onwards in the 40 most deprived districts in the Netherlands. Interventions varied from improvements in the built environment to activities promoting social cohesion.}

Methods We accessed repeated cross-sectional data from the annual Health Interview Survey, for the period 2004-2011 among adults (n target districts=1445, $n$ rest of the Netherlands $=44$ 795). We used multilevel logistic regression models to compare the development of mental health in the target districts with the rest of the Netherlands and with comparably deprived districts. Results were presented as 'slope estimates' with corresponding 95\% Cls. Finally, we analysed the trends by gender and by the intensity of the programme. Results The trend change in mental health between the intervention and preintervention period was approximately the same in the target districts as in broadly comparably deprived control districts ( $\Delta$ slope 0.06 (-0.08 to 0.20)). However, among women, a tendency was found towards more positive trend changes in the target districts compared with control districts ( $\Delta$ slope $0.17(-0.01$ to 0.34$)$ ). Those districts that implemented an intensive programme experienced an improvement in mental health, while residents of the comparably deprived control districts experienced a deterioration, resulting in a statistically significantly more positive trend change between the preintervention and intervention period in those target districts ( $\Delta$ slope 0.19 (0.01 to 0.38$)$ ).

Conclusions Implementing an urban regeneration programme with a wide range of intensive interventions may be effective in promoting good mental health. Further research is required to examine which mix of interventions is needed for the programme to be effective.

\section{INTRODUCTION}

When striving for health equity, we need to find ways to improve the circumstances in which people are born, grow, live, work and age. ${ }^{1}$ Urban regeneration programmes that target deprived neighbourhoods are one possible way of tackling so-called social determinants of health such as employment, housing and social cohesion. Experiences thus far have failed to provide conclusive empirical evidence of the positive health impacts of such programmes. Although the available evidence seems to indicate an impact on mental health, this evidence is also mixed.

An evaluation of the New Deal for Communities programme-one of the most intensive programmes of this kind ever to be introduced in the UK-found a positive change in mental health for the target population compared with comparison areas. ${ }^{2}$ Women showed a more positive improvement than men. ${ }^{3}$ In a longitudinal sample, the overall differences between the target and comparison populations disappeared after adjustment for baseline health and socioeconomic differences, ${ }^{2}$ although the most disadvantaged groups still showed a greater improvement in mental health than their counterparts in control areas. ${ }^{4}$ An evaluation of the GoWell regeneration programme in Glasgow indicated a small improvement in mental health compared with the control group, although it was observed for those residents who were exposed to housing improvements only. ${ }^{5}$ Also, a quasi-experimental study on urban renewal in Barcelona indicated a positive effect on mental health. ${ }^{6}$ Other small-scale programmes in the UK and Norway also reported improvements in mental health following the initiatives. ${ }^{7-9}$ A major limitation of these small-scale studies was that they did not include control districts. In addition, some studies had small sample sizes, which limited their ability to detect preintervention and postintervention differences. ${ }^{10}{ }^{11}$ Moreover, none of them evaluated trends over time before the interventions started.

The interventions delivered within urban regeneration usually included a broad range of activities, varying from investments to improve the built environment or housing quality to activities aimed at reducing crime and promoting safety and social cohesion. Previous studies tended not to report in detail on the type or intensity of activities delivered in relation to the observed impact. ${ }^{12}$ However, a detailed appraisal of their content, duration and scale is imperative to understanding the conditions in which regeneration might have an impact on health.

There is a need for comprehensive studies on large-scale urban regeneration programmes that include control areas and investigate preintervention and postintervention trend changes in mental health, and explore whether these changes vary by the intensity of the programme. In the Netherlands, such an opportunity arose with the introduction of the 'District Approach'. The Dutch government launched this initiative in 2007, and implementation began in July 2008. Between then and 2012, approximately 5 billion euros were invested to ameliorate problems with employment, educational level, housing conditions or residential environment, safety and social cohesion in the 40 most deprived districts (hereafter called target 
districts). Each district implemented socioeconomic and environmental interventions tailored to suit specific local needs. There were large variations in the number of residents the interventions reached, the degree of change achieved and/or the number of different types of activities. ${ }^{12}$

The aim of this paper was to evaluate the District Approach's short-term impact on mental health, using a quasi-experimental design. First, we investigated whether the mental health trend in target districts was more positive during the first years following the implementation compared with the trend before that time. We compared the development of mental health in the target districts with the development in control districts. Furthermore, we examined whether these trends varied according to gender and the intensity of the urban regeneration programme employed.

\section{METHODS}

\section{Study design and study population}

Intervention districts

The intervention group consisted of all deprived districts targeted by the District Approach. We accessed repeated crosssectional data from the Dutch Health Interview Survey (HIS) conducted by Statistics Netherlands. The HIS is an annual nationwide survey among non-institutionalised persons aged 0 and older. Each month, a person-based sample is drawn from the Dutch population register. From 2004 to 2009, respondents could participate by face-to-face interview at home. From 2010, respondents have been able to participate by internet, phone or face-to-face interview. A second part of the questionnaire contains more sensitive topics such as mental health and can be completed by respondents aged 12 and older using a written questionnaire, or by internet (from 2010 on). The annual response rate is $60-65 \%$ for the main survey; among those who responded, the response rate for the second part was 80\% (2004-2009) and 55\% (2010-2011). We selected data from the years 2004-2011 among adults aged 18 and older. Data from 46240 respondents were included.

\section{Control districts}

We compared the development of mental health in the target districts with the trend in three types of control districts. The first two types were identified using propensity score matching $(\mathrm{PSM})^{13-16}$ (see web appendix). We used PSM to select areas that are similar with regard to their living circumstances, physical and social neighbourhood characteristics, and safety (13 indicators) at the start of the District Approach (2008). First, for maximum comparability, we matched the target districts with control districts with exactly the same range of propensity scores as the target districts (narrow definition). Owing to the relatively small number of districts in this control group, we also included a second, larger control group, in which we matched the target districts with control districts that belong to the $10 \%$ of districts with the highest propensity scores (broad definition). The difference between the trend in the intervention districts and the trend in these comparably deprived districts could theoretically be attributed to the urban regeneration programme. The third type of control group includes all other (postcode) areas in the Netherlands. By comparing the secular trend in this control group with that in the first two categories of control groups, we could get insight into other possible developments affecting mental health, which could help us to interpret the (absence of an) intervention effect.

\section{Measures}

Mental health

The outcome variable was perceived mental health as measured by the five-item Mental Health Inventory (MHI-5). ${ }^{17}$ It is especially a good predictor of mood disorders and a satisfactory screening instrument for some anxiety disorders. ${ }^{18}$ Research has shown that self-reported mental ill health measured with the MHI-5 is strongly correlated with psychiatrists' diagnoses. ${ }^{19} 20$ It contains the following five questions: During the last 4 weeks, how often (1) have you been a very nervous person? (2) have you felt downhearted and blue? (3) have you felt calm and peaceful? (4) have you felt so down in the dumps that nothing could cheer you up? and (5) have you been a happy person? Each item has six possible answers ranging from 'all of the time' to 'never'. The total score was obtained by reversing the answers to the third and fifth questions, summing up the scores and transforming this score to a scale from 0 to 100 . A higher score indicates better mental health. On the basis of a Dutch validation study, ${ }^{21}$ we dichotomised this score into fair or good $(>60)$ and less than fair or good $(\leq 60)$.

\section{Intensity of urban regeneration programme}

For each target district, we made an inventory of types of interventions, within five policy areas: unemployment, educational level, housing conditions, safety and social cohesion. We distinguished 18 types of interventions. On the basis of the number of residents reached or magnitude of environmental change achieved, the intensity of each type of intervention was classified as 'less intensive' (0), 'moderately intensive' (1) or 'more intensive' (2). For four target districts, no detailed information on activities was available. For each of the other districts, an average score was calculated for the 18 types of activities. We distinguished 19 target districts with a more intensive programme (range: 0.94-1.33) and 17 target districts with a less intensive programme (range: 0.39-0.89) (table 1). The more intensive programmes employed activities within a larger number of types of activities and incorporated measures that spanned the different policy areas. This classification (method and outcome) has been described in detail elsewhere. ${ }^{12}$

\section{Sociodemographic confounders}

Several individual-level covariates were used to control for potential confounding: age (continuous variable), gender (male vs female), household composition (partner/married with or without children, single with or without children), ethnicity (Dutch origin, non-Dutch origin and origin unknown) and socioeconomic status (SES). Two indicators of SES were included: education measured as highest educational level achieved (primary, secondary, upper secondary or tertiary education) and equivalent disposable household income (categorised in quintiles, with cut-off points at $€ 15865$, €20 000, $€ 24404$ and $€ 30$ 900). Most covariates were obtained from the HIS questionnaire. Ethnicity and household income (both at individual level) were derived from the National Population Register and the National Tax Register, respectively.

\section{Statistical analyses}

Multilevel multivariate logistic regression models were used to assess the change in prevalence of perceived mental health per half-year in the target and control districts. Survey dates were grouped into half-year sections. The implementation of the District Approach started on average in mid-2008. The trend parameter was estimated for the preintervention (January 2004-June 2008) and intervention (July 2008-December 2011) 
Table 1 Characteristics of the study population

\begin{tabular}{|c|c|c|c|c|}
\hline Characteristics* $\dagger$ & 40 target districts & $\begin{array}{l}\text { Comparably deprived } \\
\text { districts PSM 'narrow'ł }\end{array}$ & $\begin{array}{l}\text { Comparably deprived } \\
\text { districts PSM 'broad'‡ }\end{array}$ & $\begin{array}{l}\text { Rest of the } \\
\text { Netherlands }\end{array}$ \\
\hline \multicolumn{5}{|l|}{ Numbers (n) } \\
\hline Four-digit postcodes & 83 & 77 & 303 & 3402 \\
\hline Individuals in total & 1445 & 1574 & 6163 & 44802 \\
\hline Individuals per half-year (mean $\pm S D$ ) & $90 \pm 13.2$ & $98 \pm 14.7$ & $385 \pm 32.2$ & $2800 \pm 287.8$ \\
\hline Age $($ mean $\pm S D)$ & $46.1 \pm 17.5$ & $45.6 \pm 16.6$ & $46.4 \pm 16.6$ & $47.0 \pm 16.8$ \\
\hline \multicolumn{5}{|l|}{$\operatorname{Sex}(\%)$} \\
\hline Female & 52.8 & 54.0 & 52.2 & 50.7 \\
\hline Male & 47.2 & 46.0 & 47.8 & 49.3 \\
\hline \multicolumn{5}{|l|}{ Household composition (\%) } \\
\hline Partner/married with child(ren) & 35.5 & 36.5 & 35.9 & 41.0 \\
\hline Partner/married without child(ren) & 24.6 & 28.9 & 29.8 & 34.8 \\
\hline Single without child(ren) & 27.0 & 24.7 & 25.8 & 18.4 \\
\hline Single with child(ren) & 9.5 & 7.5 & 6.3 & 4.4 \\
\hline Other & 3.4 & 2.4 & 2.2 & 1.4 \\
\hline \multicolumn{5}{|l|}{ Ethnicity (\%) } \\
\hline Ethnic Dutch & 64.0 & 74.0 & 78.6 & 87.5 \\
\hline Non-Dutch, Western & 9.8 & 9.8 & 9.9 & 7.6 \\
\hline Non-Dutch, non-Western & 23.0 & 14.0 & 9.7 & 3.8 \\
\hline Non-Dutch, origin unknown & 3.1 & 2.2 & 1.8 & 1.2 \\
\hline \multicolumn{5}{|l|}{ Education (\%) } \\
\hline Primary & 20.8 & 17.1 & 15.6 & 12.3 \\
\hline Lower secondary & 26.0 & 21.1 & 20.7 & 22.8 \\
\hline Upper secondary & 30.2 & 28.8 & 31.7 & 37.0 \\
\hline Tertiary & 23.0 & 33.1 & 32.1 & 27.9 \\
\hline \multicolumn{5}{|l|}{ Income (\%) } \\
\hline First quintile $(<€ 15865)$ & 32.2 & 25.2 & 23.9 & 20.4 \\
\hline Second quintile (€15 865-€20 000) & 24.1 & 21.6 & 20.6 & 20.0 \\
\hline Third quintile (€20 000-€24 404) & 18.0 & 18.9 & 19.9 & 20.0 \\
\hline Fourth quintile (€24 404-€30 900) & 15.0 & 16.3 & 17.6 & 20.0 \\
\hline Fifth quintile (>€30 900) & 10.8 & 18.0 & 18.0 & 19.7 \\
\hline
\end{tabular}

periods. The difference in trends between these periods was assessed using an interaction term for half-year and period. Furthermore, to test for a difference in trend change between target districts and control districts, we included a higher order interaction term for half-year, period and district.

To assess the potential differential effects according to gender, we stratified the analyses by gender. The role of intensity was assessed by stratifying the analyses by programme intensity (target districts with less intensive vs more intensive activities).

To account for possible clustering of individuals within postcode areas, we applied mixed models that included random intercepts. Level 1 of the multilevel analysis represented individuals, and level 2 represented the postcode areas. Results were presented as coefficients or 'slope estimates' with corresponding 95\% CIs. For two reasons, we chose not to present ORs. First, the ORs would be a poor approximation of relative risks, given the high prevalence of the outcome measure. Second, the primary aim of the statistical models was to assess the difference in preintervention and intervention trend. In this particular case, the use of 'slope estimates' has the practical advantage of showing in the most direct way whether the (difference in) prevalence rates increase (positive slope) or decrease (negative slope) over time. The analyses were performed using SPSS V.14 and Stata V.11.0 software.

\section{RESULTS}

Compared with all types of control districts, a higher percentage of residents of the target districts were single, of non-Dutch origin, less educated and had a lower income (table 1).

Figure 1 shows the trends in prevalence of fair or good mental health between 2004 and 2011. As expected, this prevalence was lowest in the target districts and highest in the rest of the Netherlands. In the target districts, the prevalence remained approximately the same in the preintervention and intervention period (about $77.0 \%$ ). In the comparably deprived areas (broad definition), after increasing in the preintervention period (from $81.4 \%$ to $85.0 \%$ ), the prevalence of fair or good mental health slightly decreased in the intervention period (from $83.9 \%$ to $82.1 \%)$. A similar trend change was observed in the rest of the Netherlands.

The results of the regression models confirmed these patterns (table 2). In the deprived target districts, the trend in mental health was fairly stable in the preintervention and intervention period. The trend change was small and not statistically significant ( $\Delta$ slope $-0.01(-0.13$ to 0.11$)$ ). In both control groups of comparably deprived districts, there was a negative trend change between the preintervention and intervention period, although it was statistically significant in the 'broad definition' group only $(\Delta$ slope $-0.07(-0.13$ to -0.00$))$. However, the difference 
Figure 1 Trends in fair or good mental health between 2004 and 2011 in 40 target districts, comparably deprived districts and the rest of the Netherlands. The prevalence for each that specific half-year and the half-year before and after (a moving average). half a year is the average prevalence of

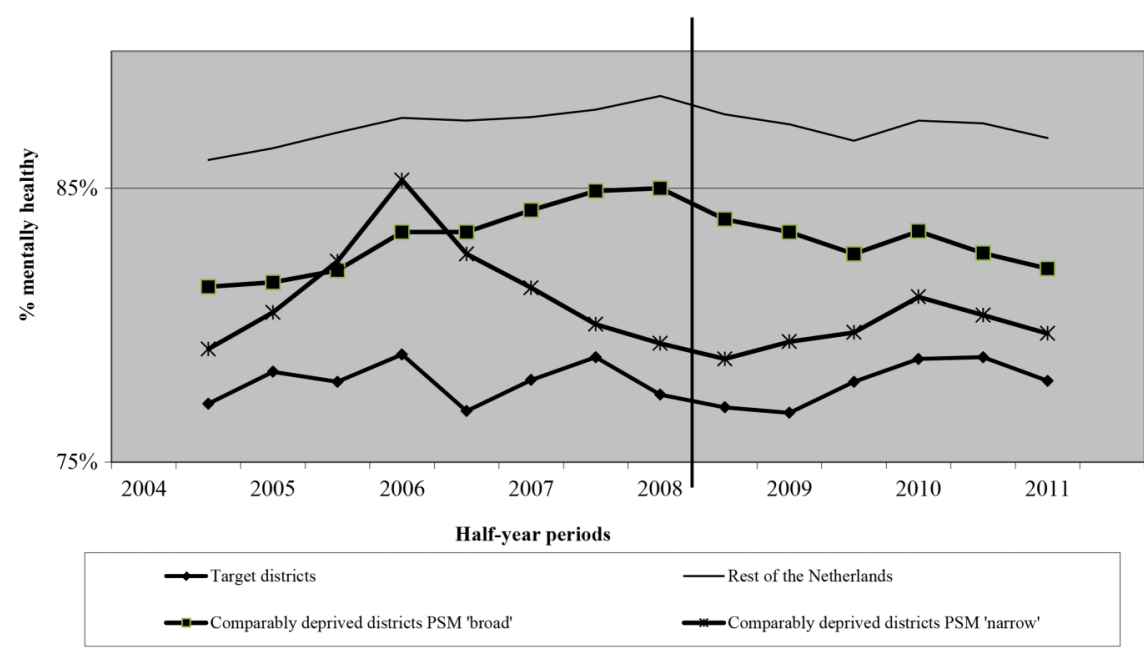

between the relatively stable trend in the deprived target districts and the negative trend in the control districts was not statistically significant (eg, $\Delta$ slope 0.06 (-0.08 to 0.20$)$ 'broad definition' group). A similar pattern was found for the comparison group 'rest of the Netherlands'.

The stable trend in the target districts over the entire period appears to conceal different patterns for men and women (table 3). Female residents of the 40 target districts reported a deterioration in mental health in the preintervention period (from $74.6 \%$ to $71.4 \%$ ) and a small improvement in the intervention period (from $70.2 \%$ to $73.0 \%$ ). The trend among women living in control districts (comparably deprived districts (PSM 'broad definition')) showed the reverse pattern, with a significantly negative trend change (eg, $\Delta$ slope $-0.09(-0.18$ to -0.01). As a result, compared with these control districts, a tendency towards a more positive trend change was found among women in the target districts, although this was not statistically significant ( $\Delta$ slope $0.17(-0.01$ to 0.34$)$ ). This positive trend was not observed among men ( $\Delta$ slope $-0.13(-0.35$ to 0.10$)$ ) owing to the fact that male residents of the target districts reported a deterioration in mental health in the intervention period (from $87.0 \%$ to $82.9 \%$ ).

Residents of the 19 target districts where the urban regeneration programme was most intensive reported a sharp decrease in the prevalence of fair or good mental health in the preintervention period, followed by an improvement in the intervention period (table 4$)$. The trend change was more positive than in comparably deprived areas ( $\Delta$ slope 0.19 (0.01 to 0.38 ) 'broad definition')) and the rest of the Netherlands ( $\Delta$ slope $0.18(0.01$ to 0.36$)$ ). In contrast, in the 17 'lowintensity' target districts, the prevalence of fair or good mental health declined in the intervention period (from $80.5 \%$ to $76.9 \%$ ). The difference between their preintervention and intervention trends was approximately the same as the trend change in all control districts.

\section{DISCUSSION}

We investigated whether the mental health trend change following the implementation of an urban regeneration programme in deprived districts was more positive than that in control districts. Compared with comparably deprived control districts, target districts tended to show a more positive trend change in mental health between the preintervention and intervention period, although for women only. For males, the trend change in the target districts did not differ from that in the control districts. When stratified by intensity of the implemented approach, a positive trend change in mental health between the intervention and preintervention period was apparent in those districts where activities were implemented on a larger scale and across different policy areas compared with the control groups. The

Table 2 Trend change in fair or good mental health between the preintervention (2004-2008) and intervention (2008-2011) period in 40 target districts, comparably deprived districts and the rest of the Netherlands

\begin{tabular}{|c|c|c|c|}
\hline \multirow[b]{3}{*}{ Type of area } & \multicolumn{3}{|c|}{ Trend in fair or good mental health (slope estimate* $(95 \% \mathrm{CI})$ ) } \\
\hline & \multicolumn{3}{|l|}{ Period } \\
\hline & $\begin{array}{l}\text { Preintervention period } \\
(2004-2008)\end{array}$ & $\begin{array}{l}\text { Intervention period } \\
(2008-2011)\end{array}$ & $\begin{array}{l}\text { Intervention vs preintervention periodt } \\
\text { (difference in difference) }\end{array}$ \\
\hline Target districts & $-0.01(-0.06$ to 0.04$)$ & $-0.02(-0.11$ to 0.06$)$ & $-0.01(-0.13$ to 0.11$)$ \\
\hline Comparably deprived districts PSM 'narrow' & $-0.01(-0.07$ to 0.04$)$ & $-0.04(-0.12$ to 0.05$)$ & $-0.02(-0.14$ to 0.10$)$ \\
\hline Target districts vs comparably deprived districts PSM 'narrow' $\dagger$ & & & $0.00(-0.17$ to 0.17$)$ \\
\hline Comparably deprived districts PSM 'broad' & $0.02(-0.01$ to 0.05$)$ & $-0.05(-0.10$ to -0.01$) \ddagger$ & $-0.07(-0.13$ to -0.00$) \ddagger$ \\
\hline Target districts vs comparably deprived districts PSM 'broad' $\dagger$ & & & $0.06(-0.08$ to 0.20$)$ \\
\hline Rest of the Netherlands & $0.02(0.01$ to 0.03$) \ddagger$ & $-0.05(-0.07$ to -0.03$) \ddagger$ & $-0.07(-0.09$ to -0.04$) \ddagger$ \\
\hline Target districts vs rest of the Netherlands $†$ & & & $0.06(-0.07$ to 0.18$)$ \\
\hline
\end{tabular}


Table 3 Trend change in fair or good mental health between the preintervention (2004-2008) and intervention (2008-2011) period in 40 target districts, comparably deprived districts and the rest of the Netherlands, by gender

\begin{tabular}{|c|c|c|c|c|}
\hline \multirow[b]{3}{*}{ Gender } & \multirow[b]{3}{*}{ Type of area } & \multicolumn{3}{|c|}{ Trend in fair or good mental health (slope estimate* $(95 \% \mathrm{Cl})$ ) } \\
\hline & & \multicolumn{3}{|l|}{ Period } \\
\hline & & $\begin{array}{l}\text { Preintervention period } \\
(2004-2008)\end{array}$ & $\begin{array}{l}\text { Intervention period } \\
(2008-2011)\end{array}$ & $\begin{array}{l}\text { Intervention vs preintervention } \\
\text { periodt (difference in difference) }\end{array}$ \\
\hline \multirow[t]{7}{*}{ Females } & Target districts & $-0.05(-0.11$ to 0.01$)$ & $0.01(-0.10$ to 0.13$)$ & $0.07(-0.09$ to 0.22$)$ \\
\hline & Comparably deprived districts PSM 'narrow' & $0.01(-0.05$ to 0.08$)$ & $-0.04(-0.14$ to 0.07$)$ & $-0.05(-0.20$ to 0.11$)$ \\
\hline & Target districts vs comparably deprived districts PSM 'narrow'† & & & $0.13(-0.09$ to 0.34$)$ \\
\hline & Comparably deprived districts PSM 'broad' & 0.04 (0.01 to 0.08$) \ddagger$ & $-0.05(-0.11$ to 0.01$)$ & $-0.09(-0.18$ to -0.01$) \ddagger$ \\
\hline & Target districts vs comparably deprived districts PSM 'broad'† & & & $0.17(-0.01$ to 0.34$)$ \\
\hline & Rest of the Netherlands & $0.02(0.01$ to 0.04$) \neq$ & $-0.04(-0.06$ to -0.02$) \ddagger$ & $-0.06(-0.10$ to -0.03$) \ddagger$ \\
\hline & Target districts vs rest of the Netherlandst & & & $0.13(-0.03$ to 0.29$)$ \\
\hline \multirow[t]{7}{*}{ Males } & Target districts & $0.05(-0.03$ to 0.14$)$ & $-0.10(-0.24$ to 0.04$)$ & $-0.15(-0.36$ to 0.05$)$ \\
\hline & Comparably deprived districts PSM 'narrow' & $-0.05(-0.14$ to 0.04$)$ & $-0.04(-0.18$ to 0.10$)$ & $0.01(-0.19$ to 0.22$)$ \\
\hline & Target districts vs comparably deprived districts PSM 'narrow' $\dagger$ & & & $-0.20(-0.48$ to 0.09$)$ \\
\hline & Comparably deprived districts PSM 'broad' & $-0.02(-0.07$ to 0.02$)$ & $-0.05(-0.12$ to 0.02$)$ & $-0.03(-0.13$ to 0.07$)$ \\
\hline & Target districts vs comparably deprived districts PSM 'broad' $\dagger$ & & & $-0.13(-0.35$ to 0.10$)$ \\
\hline & Rest of the Netherlands & $0.02(-0.00$ to 0.03$)$ & $-0.06(-0.09$ to -0.03$) \ddagger$ & $-0.07(-0.12$ to -0.03$) \ddagger$ \\
\hline & Target districts vs rest of the Netherlands $t$ & & & $-0.08(-0.29$ to 0.13$)$ \\
\hline
\end{tabular}

${ }^{*}$ Adjusted for age, gender, household composition, ethnicity, education and income.

tReference category.

$\ddagger$ The association is statistically significant by $p \leq 0.05$, two-sided test.

PSM, propensity score matching.

trend change in the 'low-intensity' districts was comparable with that in the comparably deprived control districts.

\section{Limitations of the study design}

Owing to the quasi-experimental design, the health impact we observed among women and in the districts intervening with high intensity might not actually exist. As the deprived districts were not assigned randomly, the target and control districts might differ in some respects. We have taken several measures to address potential confounding. First, we used PSM to select control districts that were most similar to the target districts with regard to liveability when the implementation of the District Approach began. It should be acknowledged, however, that there were still substantial differences between the target and control districts, even for the control districts with the same range of propensity scores as the target districts (narrow

Table 4 Trend change in fair or good mental health between the preintervention (2004-2008) and intervention (2008-2011) period in 19 target districts intervening with high intensity and 17 districts with low intensity, comparably deprived districts and the rest of the Netherlands

\begin{tabular}{|c|c|c|c|c|}
\hline \multirow[b]{3}{*}{ Intensity } & \multirow[b]{3}{*}{ Type of area } & \multicolumn{3}{|c|}{ Trend in fair or good mental health (slope estimate* $(95 \% \mathrm{CI})$ ) } \\
\hline & & \multicolumn{3}{|l|}{ Period } \\
\hline & & $\begin{array}{l}\text { Preintervention } \\
\text { period (2004-2008) }\end{array}$ & $\begin{array}{l}\text { Intervention period } \\
(2008-2011)\end{array}$ & $\begin{array}{l}\text { Intervention vs preintervention } \\
\text { periodt (difference in difference) }\end{array}$ \\
\hline \multirow[t]{7}{*}{ More intensive } & Target districts & $-0.07(-0.14$ to 0.01$)$ & $0.05(-0.07$ to 0.17$)$ & $0.12(-0.06$ to 0.29$)$ \\
\hline & Comparably deprived districts PSM 'narrow' & $-0.02(-0.07$ to 0.04$)$ & $-0.02(-0.10$ to 0.07$)$ & $-0.00(-0.13$ to 0.12$)$ \\
\hline & Target districts vs comparably deprived districts PSM 'narrow' $\dagger$ & & & $0.13(-0.08$ to 0.34$)$ \\
\hline & Comparably deprived districts PSM 'broad' & $0.02(-0.01$ to 0.04$)$ & $-0.04(-0.09$ to 0.00$)$ & $-0.06(-0.13$ to 0.00$)$ \\
\hline & Target districts vs comparably deprived districts PSM 'broad' $\dagger$ & & & 0.19 (0.01 to 0.38$) \ddagger$ \\
\hline & Rest of the Netherlands & $0.02(0.01$ to 0.03$) \ddagger$ & $-0.05(-0.07$ to -0.03$) \ddagger$ & $-0.07(-0.09$ to -0.04$) \ddagger$ \\
\hline & Target districts vs rest of the Netherlands $t$ & & & 0.18 (0.01 to 0.36$) \ddagger$ \\
\hline \multirow[t]{7}{*}{ Less intensive } & Target districts & $0.03(-0.05$ to 0.11$)$ & $-0.09(-0.23$ to 0.04$)$ & $-0.12(-0.32$ to 0.07$)$ \\
\hline & Comparably deprived districts PSM 'narrow' & $-0.01(-0.06$ to 0.04$)$ & $-0.04(-0.13$ to 0.04$)$ & $-0.03(-0.16$ to 0.09$)$ \\
\hline & Target districts vs comparably deprived districts PSM 'narrow' $\dagger$ & & & $-0.11(-0.33$ to 0.12$)$ \\
\hline & Comparably deprived districts PSM 'broad' & $0.02(-0.01$ to 0.05$)$ & $-0.05(-0.10$ to -0.01$) \ddagger$ & $-0.07(-0.14$ to -0.01$) \ddagger$ \\
\hline & Target districts vs comparably deprived districts PSM 'broad' $\dagger$ & & & $-0.06(-0.26$ to 0.14$)$ \\
\hline & Rest of the Netherlands & $0.02(0.01$ to 0.03$) \ddagger$ & $-0.05(-0.07$ to -0.03$) \ddagger$ & $-0.07(-0.09$ to -0.04$) \ddagger$ \\
\hline & Target districts vs rest of the Netherlands $t$ & & & $-0.06(-0.25$ to 0.14$)$ \\
\hline
\end{tabular}

\footnotetext{
*Adjusted for age, gender, household composition, ethnicity, education and income.

tReference category.

$\ddagger$ The association is statistically significant by $p \leq 0.05$, two-sided test.

PSM, propensity score matching.
} 
definition). As the districts have been matched on the basis of environmental variables, the match was the poorest for sociodemographic characteristics. Since the Dutch District Approach aimed to improve the living circumstances in the 40 most deprived districts in the Netherlands, it was, by definition, impossible to select control districts that were equally deprived in sociodemographic terms. Residual confounding may thus have affected our results. However, this bias is limited because of our detailed control for sociodemographic characteristics at the individual level. Second, in the statistical analyses, we controlled for a number of potential confounders at the level of individual residents, in particular the aforementioned sociodemographic characteristics. Nonetheless, residual confounding cannot be ruled out. In addition, selective migration might have been responsible for the positive trends in mental health. It has been suggested that the implementation of the District Approach stimulated migration of people with a favourable socioeconomic position and good mental health. If so, such trends may have caused some of the positive trends we observed between the preintervention and intervention period. However, a previous study on deprived Dutch neighbourhoods showed that selective migration did not strongly affect the average district health situation, as movers and new settlers had similar levels of health. ${ }^{22}{ }^{23}$ Additionally, another study reported very small differences in the income position of movers and settlers in the target districts for the period 2009-2010. ${ }^{24}$ Finally, it has been argued that urban regeneration may stimulate the outmigration of people who achieved upward social mobility, thanks to the programme. Such outmigration would lead to an underestimation of the positive mental health impact. However, selective migration seems to have played a minor role, as adjustments for socioeconomic factors did not substantially change the observed trends.

Overall, the risk of having overestimated positive trends seems to be smaller than the reverse risk of having underestimated or having been unable to detect actual positive trends. We may have missed trends because of the rather low number of respondents per target district per period. As the number of comparably deprived control districts in a strict sense (narrow definition) was rather small, we chose also to include a broader selection of deprived neighbourhoods (broad definition). As expected, we more frequently found a statistically significant difference in trend in mental health between the intervention and control districts using the broad definition. Even in that case, however, trends could be estimated with only limited precision. In addition, the low available number of respondents reduced opportunities for subgroup analyses (such as by gender and intensity simultaneously). Moreover, this evaluation study has a limited intervention period of 3.5 years. This is especially limited as the implementation of activities continued during this period. In addition, the mental health impact of some of the activities implemented, such as educational programmes and interventions promoting social cohesion, might take a long time to establish. The short study period thus kept us from observing any potential long-term impact the programme might have.

\section{Interpretation of results}

Our results add to a growing body of knowledge suggesting that urban regeneration programmes can lead to better mental health among residents of deprived neighbourhoods. This body of knowledge builds on common explanatory models of health inequalities ${ }^{1}$ that explicitly acknowledge that health is fundamentally dependent on resources and services determined by actors who are mainly outside of the health sector.
Consequently, intersectoral or health-in-all approaches have considerable potential to positively affect population health. ${ }^{25}$ Urban regeneration programmes are one possible way of implementing measures across different sectors at the local level.

No impact was observed in districts that implemented a less intensive programme, suggesting that the lack of impact among the 40 target districts taken as a whole might have been diluted by the districts whose programmes were less intensive. This would imply that, for an urban renewal programme to have a demonstrable impact, such initiatives must be implemented with a high level of intensity in terms of duration, scale and coverage of different types of policy areas. Although we analysed the activities with respect to contents, duration and scale in greater detail than most other evaluations studies, ${ }^{12}$ we cannot draw conclusions as to the specific mix of interventions responsible for the observed positive trends. Future analyses of health trends in areas with specific intervention packages based on a larger number of respondents per area will probably shed more light on this issue. In addition, a theory-based, realist approach might be applied to further understand how a regeneration programme impacts health. ${ }^{26}$

With natural experiments, there is always the risk that other developments will disrupt the intended effect of the intervention. In the case of the Dutch District Approach, the most disruptive factor seems to have been the recent economic crisis, which began at almost the same time as the activities implemented. The negative trend in mental health in the intervention period in the Netherlands as a whole, as well as in the deprived districts that served as control groups, might reflect the impact of the economic crisis. The fact that the trend in mental health in the target districts remained stable (women) or improved slightly (in areas with the most intensive approach) during this period might cautiously be interpreted as indicating that the urban regeneration programme was able to keep this negative health impact of the economic crisis from arising in these areas.

Our results were in agreement with our hypothesis that the effect would be stronger among women. This might be related to the relatively low labour market participation among Dutch women, particularly among those from lower socioeconomic groups. As a consequence, women might spend more time in their neighbourhoods than men, making them probably more sensitive to the health impact of an urban renewal programme.

\section{CONCLUSION}

Implementing an urban regeneration programme with a wide range of intensive interventions may be effective in promoting good mental health. Further research is required to examine which mix of interventions is needed for the programme to be effective.

\section{What is already known on this subject}

- Previous studies provide mixed evidence on the impact of urban regeneration programmes on mental health.

- There is a need for evaluation studies that include control areas and investigate trend changes in health between the intervention and preintervention period, and explore whether these changes vary by the intensity of the programme.

- In the Netherlands, such an opportunity arose with the introduction of the 'District Approach' in 40 deprived neighbourhoods. 


\section{What this study adds}

- As compared to control areas, a positive trend change in mental health between the intervention and preintervention period was apparent among women and in those districts where activities were implemented on a larger scale and across different policy areas.

- Further research should shed more light on the mix of interventions that is needed for an urban renewal programme to have an impact on mental health.

Acknowledgements We are grateful to Statistics Netherlands for preparing microlevel datasets and for providing access to these data.

Contributors BJ-G has designed the research questions and plan of analyses, developed the statistical procedures followed, performed the statistical analyses, interpreted the results and was the main author of the manuscript. DK has developed the statistical procedures followed and has contributed to the interpretation of the work and several versions of the manuscript. J-WB has put in his expert knowledge of the data used and contributed to the interpretation of the work and several versions of the manuscript. MD, HAMvO, AEK and KS have all contributed to the development of the research questions and research plan, the statistical procedures followed and the interpretation of the work and several versions of the manuscript.

Funding This research was part of the URBAN40 study, which is supported by a grant from the Netherlands Organisation for Health Research and Development (ZonMw) Grant number 201010009.

Competing interests None declared.

Provenance and peer review Not commissioned; externally peer reviewed.

Data sharing statement The manuscript was based on already available data sources from third parties that have been analysed to answer our research question.

\section{REFERENCES}

1 World Health Organization/Commission on the Social Determinants of Health. Closing the gap in a generation. Health equity through action on the social determinants of health. Geneva: WHO, 2008.

2 Batty E, Beatty C, Foden M, et al. The New Deal for Communities experience: a final assessment: The New Deal for Communities evaluation: final report. Vol 7. London: Department for Communities and Local Government, 2009.

3 Pearson S, Batty E, Cook B, et al., Department for Communities and Local Government). Improving health outcomes in deprived communities: evidence from the New Deal for Communities Programme. London: DCLG, 2010.

4 Walthery $\mathrm{P}$, Stafford $\mathrm{M}, \mathrm{Nazroo} \mathrm{J}$, et al. Health trajectories in regeneration areas in England: the impact of the New Deal for Communities intervention. J Epidemiol Comm Health 2015;69:762-8.

5 Egan M, Vittal Katikireddi SV, Kearns A, et al. Health effects of neighborhood demolition and housing improvement: a propspective controlled study of 2 natural experiments in Urban renewal. Am J Public health 2013;103:e47-53.
6 Mehdipanah R, Rodriguez-Sanz M, Malmusi D, et al. The effects of an urban renewal project on health and health inequalities: a quasi-experimental study in Barcelona. J Epidemiol Comm Health 2014;68:811-17.

7 Halpern D. Mental health and the build environment. London: Taylor and Francis, 1995.

8 Blackman T, Harvey J, Lawrence $M$, et al. Neighbourhood renewal and health: evidence from a local case study. Health Place 2001;7:93-103.

9 Dalgard OS, Tambs K. Urban environment and mental health. A longitudinal study. Br J Psychiatry 1997;171:530-6.

10 Huxley $\mathrm{P}$, Evans $\mathrm{S}$, Leese $\mathrm{M}$, et al. Urban regeneration and mental health. Soc Psychiatry Psychiatr Epidemiol 2004;39:280-5.

11 Jalaludin B, Maxwell M, Saddik B, et al. A pre-and-post study of an urban renewal program in a socially disadvantaged neighbourhood in Sydney, Australia. BMC Public Health 2012;12:521.

12 Droomers $M$, Harting J, Jongeneel-Grimen B, et al. Area-based interventions to ameliorate deprived Dutch neighborhoods in practice: does the Dutch district approach address the social determinants of health to such an extent that future health impacts may be expected? Prev Med 2014;61:122-7.

13 Dehejia RH, Wahba S. Propensity score-matching methods for nonexperimental causal studies. Rev Econ Stat 2002;84:151-61.

14 Oakes JM, Johnson PJ. Propensity score matching for social epidemiology. In: Oakes JM, Kaufman JS, eds. Methods in social epidemiology. New York: Jossey-Bass, 2006:370-92.

15 Kawachi I, Subramanian SV. Neighbourhood influences on health. J Epidemiol Community Health 2007;61:3-4.

16 West SG, Duan N, Pequegnat W, et al. Alternatives to the randomized controlled trial. Am J Public Health 2008;98:1359-66.

17 Berwick DM, Murphy JM, Goldman PA, et al. Performance of a five-item mental health screening test. Med Care 1991;29:169-76.

18 Cuijpers $\mathrm{P}$, Smits N, Donker T, et al. Screening for mood and anxiety disorders with the five-item, the three-item, and the two-item Mental Health Inventory. Psychiatry Res 2009;168:250-5.

19 Rumpf HJ, Meyer C, Hapke U, et al. Screening for mental health: validity of the MHI-5 using DSM-IV Axis I psychiatric disorders as gold standard. Psychiatry Res 2001;105:243-53.

20 Means-Christensen AJ, Arnau RC, Tonidandel AM, et al. An efficient method of identifying major depression and panic disorder in primary care. J Behav Med 2005;28:565-72.

21 Perenboom R, Oudshoorn K, van Herten L, et al. Life-expectancy in good mental health: establishing cut-offs points for the MHI-5 and GHQ-12. TNO-report PG/VGZI 99.067. Leiden ; 2000 (in Dutch).

22 Jongeneel-Grimen B, Droomers M, Stronks K, et al. Migration does not enlarge inequalities in health between rich and poor neighbourhoods in The Netherlands. Health Place 2011;17:988-95.

23 Jongeneel-Grimen B, Droomers M, Stronks K, et al. Migration and geographical inequalities in health in the Netherlands: an investigation of age patterns. Int J Public Health 2013;58:845-54.

24 Permentier M, Kullberg J, van Noije L. Werk aan de wijk: een quasi-experimentele evaluatie van het krachtwijkenbeleid. Den Haag: Sociaal en Cultureel Planbureau, 2013.

25 Potvin L. Intersectoral action for health: more research is needed!. Int J Public Health 2012;57:5-6.

26 Mehdipanah R, Manzano A, Borrell C, et al. Exploring complex causal pathways between urban renewal, health and health inequality using a theory-driven realist approach. Soc Sci Med 2015;124:266-74. 